\title{
Influence of Thermal Processing in High Magnetic Field on Soft Magnetic Properties and Crystallographic Texture of Non-Oriented Fe-Si Steels
}

\author{
I. Petryshynets ${ }^{a, *}$, F. KováC̆ ${ }^{a}$, J. Marcin $^{b}$ And I. ŠKorváneK ${ }^{b}$ \\ ${ }^{a}$ Division of Metals Systems, Institute of Materials Research, Watsonova 47, 04101 Košice, Slovakia \\ ${ }^{b}$ Institute of Experimental Physics, SAS, Watsonova 47, 04001 Košice, Slovakia
}

\begin{abstract}
In this work, we report on the effects of high static magnetic field on the formation of desirable crystallographic orientation of grains ("rotating" cube) during the primary recrystallization of non-oriented steels. Vacuum degassed non-oriented steel with the silicon content about $1 \mathrm{wt} \%$ was taken from industrial line after final cold rolling with $80 \%$ of deformation and then it was subjected to the laboratory annealing at temperature of primary recrystallization. Whole annealing process was carried with and without the applied external magnetic field of $14 \mathrm{~T}$. The analysis of crystallographic orientation of experimental material was studied by electron backscattered diffraction technique. The microstructural and textural observations have shown a small difference in average grain size between samples annealed with and without magnetic field as well as increase of the "rotating" Cube component and decrease of the intensity of deformation texture by application of magnetic field. The magnetic measurements show that the coercivity value of the sample annealed in the magnetic field of $14 \mathrm{~T}$ can be reduced by approximately $3 \%$ in comparison with sample annealed under the zero field conditions.
\end{abstract}

DOI: 10.12693/APhysPolA.131.783

PACS/topics: 75.50.Kj, 61.72.--y, 68.55.jm, 75.60.Nt, 75.50.Vv

\section{Introduction}

Non-oriented (NO) electrical steel sheets are soft magnetic materials of prime importance in the electrical industry and are widely used for rotating machine cores, typically motors and generators. The magnetic properties of electrical steels such as magnetization curves, permeability and specific losses are, to a large extent, correlated by two microstructural features: (i) the final texture and (ii) the average grain size $[1,2]$. The NO electrotechnical steels are characterized by uniform magnetic properties within all in-plane directions which could be provided ideally by so-called "rotating" cube texture $\{100\}\langle u v w\rangle$, where the grains have their $\{100\}$ planes parallel to the sheet surface and all possible rotational positions about this normal. This crystallographic orientation of grains is produced as a consequence of grain boundary migration during recovery, recrystallization, and grain growth that are affected by anisotropy in energy, mobility, and stored energy.

Thermal processing under the presence of external magnetic field, called also "magnetic annealing" belongs to the techniques that can be used to tailor the functional properties of magnetic materials. Annealing of materials in magnetic fields can cause a broad range of microstructural changes. Microstructural features such as preferred crystalline orientation, elongated and/or textured precipitates or directional pair ordering are attributed to the

\footnotetext{
*corresponding author; e-mail: ipetryshynets@saske.sk
}

main origins for anisotropy in various polycrystalline or multiphase magnetic materials [3]. Our field annealing experiments in Fe-based amorphous and nanocrystalline alloy systems have revealed that application of low and medium static magnetic field $(<1 \mathrm{~T})$ in longitudinal direction to the ribbon axis can result in drastic reduction of coercive field $[4,5]$. Here, the improvement of soft magnetic behavior is explained in terms of magnetic atoms pair ordering mechanism [6].

Several recent papers have demonstrated that high magnetic fields applied during thermal processing can affect the grain boundary mobility and the crystallographic texture development in FeSi electro-technical steels [7-9]. However, the observed structural changes were not particularly prominent. Our recent work has shown that the application of static magnetic field with intensity of up to $0.8 \mathrm{~T}$ can led to a slight improvement of the soft magnetic behaviour in NO FeSi steels [10].

Recent progress in design and construction of cryofree powerful high field magnets generating DC magnetic fields of 10-20 T and higher has led to an increased research interest in the study of the effects thermal processing in high magnetic fields on microstructure evolution and the related changes caused of physical properties [11]. In this work, the influence of annealing in magnetic field of $14 \mathrm{~T}$ on the development of structure, texture as well as soft magnetic properties in NO FeSi electrotechnical strips has been investigated.

\section{Experimental procedure}

The material investigated in this work was vacuum degassed NO steel with the following chemical composition, 
by wt $\%$ : $\mathrm{C}=0.006, \mathrm{Mn}=0.240, \mathrm{Si}=1.000, \mathrm{P}=0.007$, $\mathrm{Al}=0.025, \mathrm{Cu}=0.060, \mathrm{~V}=0.0320$. This steel was taken from industrial line after final cold rolling reduction $80 \%$ of deformation and thickness $0.65 \mathrm{~mm}$. Then, before the primary recrystallization annealing, each specimen was cut into strip $60 \mathrm{~mm} \times 10 \mathrm{~mm}$ with the longest side parallel to the rolling direction. The annealing was carried out in a tubular furnace that was inserted into the cryo-free superconducting magnet system. The highest available magnetic field of $14 \mathrm{~T}$ was used to maximize its influence on the potential changes of crystallographic texture and microstructure during thermomagnetic processing. The primary recrystallization annealing was realized under high vacuum conditions at two different temperatures $900^{\circ} \mathrm{C}$ and $975^{\circ} \mathrm{C}$, respectively; the annealing time was $60 \mathrm{~min}$. During the annealing, the samples were positioned in homogeneous magnetic field $\left(B_{a}\right)$, which was parallel to their rolling direction.

After annealing, the measurements of DC hysteresis loops were realized on each specimen by using Forster type $B-H$ loop tracer.

The most representative samples were chosen for the microstructure and texture analysis. The texture analysis was carried out by an electron backscattered diffraction (EBSD) method in the normal direction plane for the typical sample size $25 \mathrm{~mm} \times 10 \mathrm{~mm}$ using JEOL JSM 7000F FEG scanning electron microscope. The patterns of the backscattered electrons were detected by the "Nordlys-I" EBSD detector. The data obtained were processed by the CHANNEL-5, HKL software package. The microstructure analysis of the specimens was carried out with "Olympus Inverted System Metallurgical Microscopy GX-71".

\section{Results and discussion}

After annealing with or without the presence of magnetic field, the metallographic analyses as well as EBSD measurements were performed in order to explore the microstructure and texture development of the investigated NO steels samples. The microstructure evolution after annealing at $900{ }^{\circ} \mathrm{C}$ during $60 \mathrm{~min}$ in $14 \mathrm{~T}$ and in zerofield conditions is presented in Fig. 1a and b, respectively. Here, the both primary recrystallized microstructures are characterized by inhomogeneous distributions of grains. The samples obtained after thermal processing without and with high magnetic field have the average grain size $43 \mu \mathrm{m}$ and $58 \mu \mathrm{m}$, respectively. The microstructure of the investigated samples after annealing at $975^{\circ} \mathrm{C}$ without and with magnetic field is shown in Fig. 1c and d, respectively. As one can see, the microstructures are presented by relatively homogeneous grain matrix with average grain size of $60 \mu \mathrm{m}$ and $78 \mu \mathrm{m}$, respectively, see Fig. 1c and d. It has been shown previously that the final grain size of the FeSi samples annealed in the presence of magnetic field could be smaller or similar to the zero field treated samples [7]. In this work we have shown that the final grain size of NO steel samples thermally processed in the high magnetic field can even slightly increase.
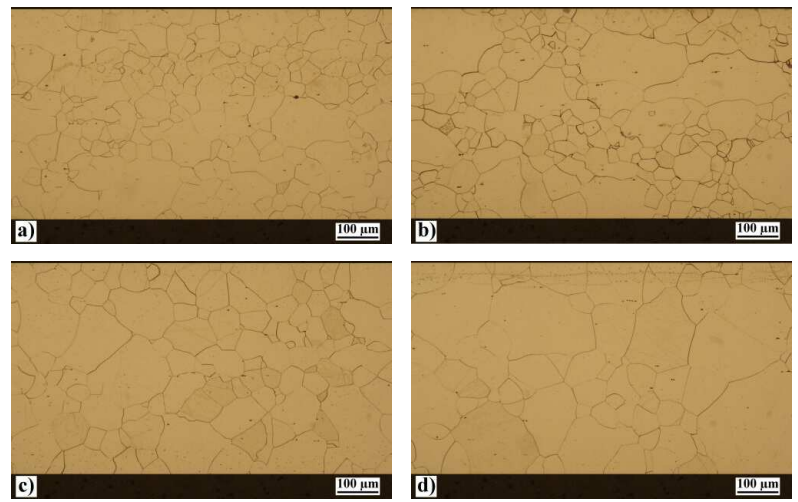

Fig. 1. Microstructure of steel obtained after annealing during 1 hour at $900^{\circ} \mathrm{C}$ : a)without magnetic field $B_{a}=0 \mathrm{~T}, \mathrm{~b}$ ) in magnetic field $B_{a}=14 \mathrm{~T}$ and at $975^{\circ} \mathrm{C}$, c) without magnetic field $B_{a}=0 \mathrm{~T}, \mathrm{~d}$ ) in magnetic field $B_{a}=14 \mathrm{~T}$
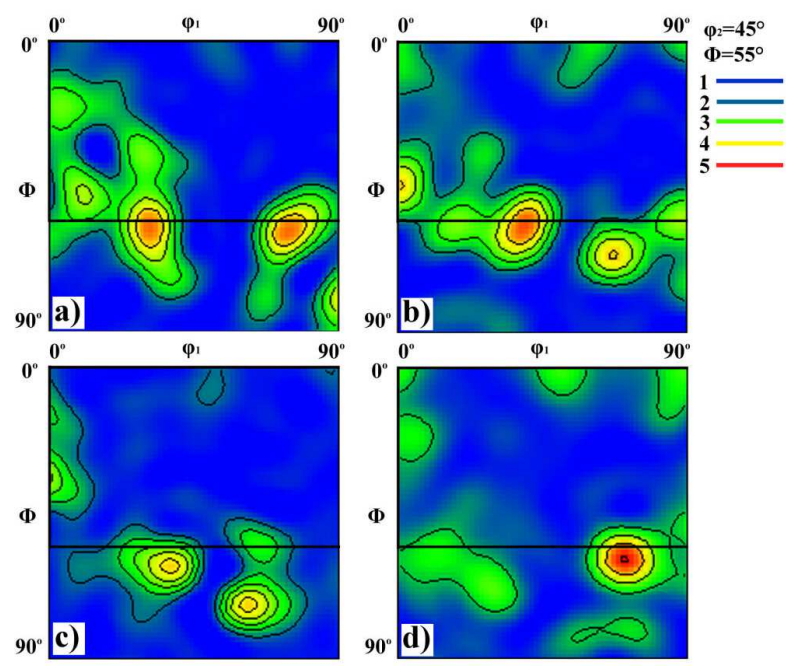

Fig. 2. The ODF section at $\phi_{2}=45^{\circ}$ represents the crystallographic orientation for experimental steel annealed at: $900^{\circ} \mathrm{C} / 1 \mathrm{~h}$, a) without magnetic field, b) with magnetic field and $975^{\circ} \mathrm{C} / 1 \mathrm{~h}, \mathrm{c}$ ) without magnetic field and d) with magnetic field.

The texture of materials is frequently represented by plotting the section of orientation distribution functions (ODF) with $\varphi_{2}=45^{\circ}$ that contain two fibers in the Euler space. These most relevant fibers for the NO silicon steels are $\gamma$ - and $\theta$-fibers which are characteristic of many rolling and recrystallization textures. For instance, $\gamma$-fiber having orientation $\{111\}\langle u v w\rangle$ and $\theta$-fiber represents the evolution of orientation $\{100\}\langle u v w\rangle$. Figure $2 \mathrm{a}-\mathrm{d}$ presents $\mathrm{ODF}$ sections taken at $\varphi_{2}=45^{\circ}$ of the investigated steel annealed at $900^{\circ} \mathrm{C}$ and $975^{\circ} \mathrm{C}$ with and without magnetic field, respectively. Developments of $\gamma$ and $\theta$-fibers are presented in Fig. 3. The $\gamma$-fiber is detrimental for the final magnetic properties of isotropic electrical steels. The result presented in Fig. 3 shows that $\gamma$-fiber decreases after annealing in magnetic field 
for both $900{ }^{\circ} \mathrm{C}$ and $975^{\circ} \mathrm{C}$. Here, a clear decrease of deformation texture $\{111\}\langle 145\rangle$ component was obtained for each temperature annealing. The ODF sections have also shown that magnetic annealing was more effective in the decrease of the volume fraction of crystals with their $\{111\}$ planes parallel to the sheet surface. The analysis of fibers obtained from ODF section has also clearly indicated a slight improvement of so-called "rotating" cube texture $\{100\}\langle u v w\rangle$, see Fig. 3b. The magnetic annealing was more effective to enhance the selectivity $\{100\}\langle 011\rangle$ component of texture and suppress $\{111\}$-axis orientation in the primary recrystallization microstructure for both samples annealed at $900^{\circ} \mathrm{C}$ and $975^{\circ} \mathrm{C}$.
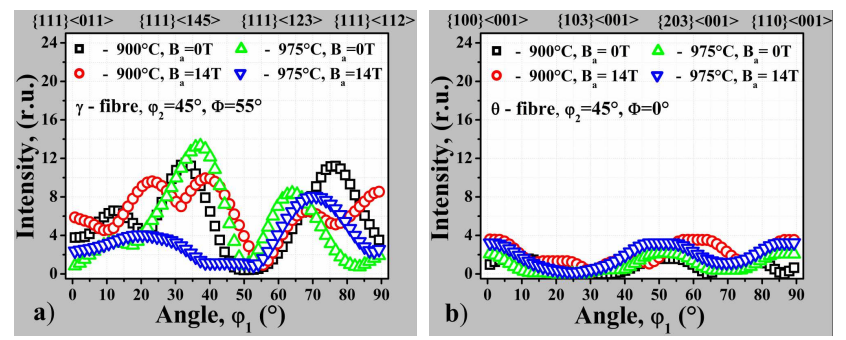

Fig. 3. The dependence of orientation density along a) $\gamma$-fiber $\left(\Phi=55^{\circ}, \phi_{2}=45^{\circ}\right)$ and b) $\theta$-fiber $\left(\Phi=0^{\circ}\right.$, $\left.\phi_{2}=45^{\circ}\right)$.
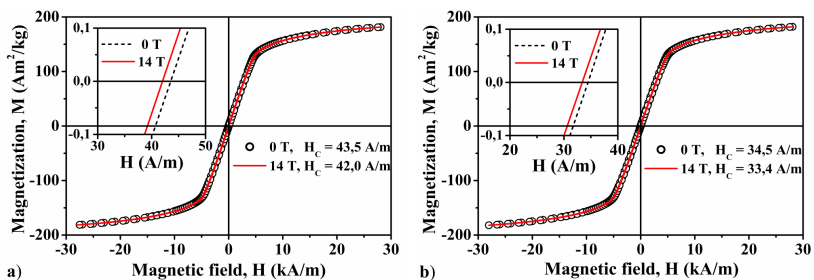

Fig. 4. DC hysteresis loops of the investigated samples after annealing at a) $900^{\circ} \mathrm{C}$ and b) $975^{\circ} \mathrm{C}$ with and without magnetic field (insets show enlarged right branches of hysteresis loop in order to depict the difference in coercive field).

Figure 4 shows the DC hysteresis loops for the NO steel samples subjected to different annealing temperature and external magnetic field. One can see that the coercivity values of the samples annealed in the magnetic field of $14 \mathrm{~T}$ are reduced by approximately $3 \%$ in comparison with samples annealed under zero field conditions. These results show that the soft magnetic properties of $\mathrm{NO} F \mathrm{FeSi}$ steels studied in this work are only marginally improved by means of annealing in the $14 \mathrm{~T}$ magnetic field.

\section{Conclusions}

In summary we have shown that field annealing has a small effect on the grain growth and texture of our FeSi steel. The intensity of deformation texture decreased after annealing in the presence of magnetic field and some improvement of "rotating" cube crystallographic texture was also detected. The magnetic measurements show that the coercivity value of the samples annealed at the magnetic field decreased by approximately $3 \%$ in comparison with samples annealed at the same conditions without external magnetic field. These findings indicate that the investigated $\mathrm{NO} \mathrm{Fe}-\mathrm{Si}$ steels exhibit only minor improvement of their microstructure parameters and soft magnetic properties after annealing in high magnetic fields.

\section{Acknowledgments}

This work was carried out within the framework of the project "Unconventional technology development of final processing of isotropic electrical steels", which is supported by the Slovak Research and Development Agency under the contract No. APVV-15-0259. This work was also partially supported by the Slovak Grant Agency VEGA, project No. $2 / 0081 / 16,2 / 0120 / 15$, and $2 / 0173 / 16$. Also, the work was realized within the frame of the project ITMS 26220220037, ITMS 26220220061, and ITMS 26220220064 .

\section{References}

[1] J.J. Sidor, K. Verbeken, E. Gomes, J. Schneider, P.R. Calvillo, L.A.I. Kestens, Mater. Character. 71, 49 (2012).

[2] D. Steiner Petrovič, B. Markoli, M. Ceh, J. Magn. Magn. Mater. 322, 3041 (2010).

[3] R.C. O‘Handley, Modern Magnetic Materials: Principles and Applications, Wiley, New York 1999.

[4] I. Škorvánek, J. Marcin, T. Krenický, J. Kováč, P. Švec, D. Janičkovič, J. Magn. Magn. Mater. 304, 203 (2006).

[5] I. Škorvánek, J. Marcin, J. Turcanova, J. Kovac, P. Svec, J. Alloys Comp. 504, S135 (2010).

[6] L. Néel, J. Phys. Radium 15, 225 (1954).

[7] C.M.B. Bacaltchuk, G.A. Castello-Branco, M. Ebrahimi, H. Garmesani, A.D. Rollett, Scr. Mater. 48 , 1343 (2003)

[8] M.Z. Salih, M. Uhlarz, F. Pyczak, H.G. Brokmeier, B. Weidenfeller, N. Al-Hamdany, W.M. Gan, Z.Y. Zhong, N. Schell, J. Magn. Magn. Mater. 381, 350 (2015).

[9] L. Liu, L. Li, J. Huang, Q. Zhai, J. Magn. Magn. Mater. 324, 2301 (2012).

[10] I. Skorvanek, J. Marcin, M. Capik, M. Varga, J. Turcanova, J. Kovac, P. Svec, D. Janickovic, F. Kovac, V. Stoyka, Magnetohydrodynamics 48, 371 (2012).

[11] I.V. Gervasyeva, E. Beaugnon, V.A. Milyutin, E.G. Volkova, D.P. Rodionov, Yu.V. Khlebnikova, D.A. Shishkin, Physica B Condens. Matter 468-469, 66 (2015). 